\title{
PERCEPÇÕES SOBRE O JARDIM BOTÂNICO DO RECIFE (JBR) ENTRE MORADORES DE SEU ENTORNO
}

\author{
Rayane Emanuela Ferreira Silva ${ }^{1}$ \\ Liliane Rosy Silva ${ }^{2}$ \\ Hugo Henrique Costa Nascimento ${ }^{3}$ \\ Rafael Ricardo Vasconcelos da Silva ${ }^{4}$
}

Resumo: Os Jardins botânicos vêm cumprindo um importante papel no desenvolvimento científico e cultural da humanidade. Neste artigo, objetivou-se analisar as percepções sobre o Jardim Botânico do Recife (JBR) entre moradores do seu entorno, visando contribuir com as ações de Educação Ambiental promovidas pela instituição. Foram aplicados questionários e realizadas análises de frequências. A maioria dos respondentes destacaram aspectos negativos sobre o local onde vivem, em virtude da precariedade de serviços públicos. Contudo, ressaltaram a importância do JBR para a proteção florestal e o lazer da comunidade. Conclui-se que as ações de Educação Ambiental podem fortalecer $o$ sentimento de pertencimento e de responsabilidades mútuas na gestão do JBR.

Palavras-chave: Educação Ambiental; Conservação Florestal; Áreas Protegidas; Gestão Participativa.

2 Jardim Botânico do Recife. E-mail: liliane rosy@yahoo.com.br

3 Universidade Federal de Alagoas. E-mail: hugohcnascimento@gmail.com

${ }^{4}$ Universidade Federal de Alagoas. E-mail: rafaelrvsilva@gmail.com 


\section{Introdução}

Desde sua origem, os Jardins Botânicos vêm contribuindo com o desenvolvimento econômico, científico e cultural da humanidade (BEDIAGA, 2007). No Brasil, os primeiros jardins botânicos foram criados ainda no período colonial, e tinham como principal objetivo a aclimatação e domesticação de plantas de interesse econômico (VEIGA et al., 2003; RODRIGUES et al., 2006; MEUNIER et al., 2009).

Nas últimas décadas, essas instituições se tornaram fortes aliadas das Estratégias Globais para a Conservação de Plantas, cujas definições se dão no âmbito da Convenção da Diversidade Biológica (CDB) - da qual o Brasil é um dos países signatários. Este documento estabelece as metas e objetivos que orientam os jardins botânicos na elaboração de programas e planos de ação. Tais esforços contribuem para que o governo brasileiro cumpra seus compromissos relativos à conservação da biodiversidade, inclusive por meio de ações de educação e sensibilização da sociedade para a importância da diversidade de plantas e a necessidade de sua conservação (JACKSON; KENNEDY, 2009; CERATI; LAZARINI, 2009). Neste cenário, muitos jardins botânicos brasileiros têm implantado programas de Educação Ambiental junto aos seus visitantes e comunidades do entorno (WILLISON, 2003; SAÍSSE; RUEDA, 2008).

Os programas educativos são importantes ferramentas para comunicação e busca por soluções de forma participativa, especialmente em áreas protegidas inseridas em regiões densamente povoadas. Nessas áreas, muitas vezes ocorrem conflitos entre gestores e comunidades vizinhas, geralmente por incompatibilidades entre os objetivos da gestão e os anseios ou necessidades das comunidades vizinhas (MARTINS, 2011; VIVACQUA; VIEIRA, 2007). Nessas situações, as estratégias de comunicação e Educação Ambiental, promovidas pela gestão dessas áreas protegidas, têm maiores chances de êxito quando elaboradas com base em informações prévias sobre a circunvizinhança, e adequadas ao seu perfil socioambiental (DIEGUES, 2008).

Neste contexto, destacam-se as pesquisas de percepção, que ajudam a levantar informações sobre a forma como as pessoas compreendem e se relacionam a um tema de interesse, como, por exemplo, o local onde estão inseridos e/ou com o qual interagem (GUERRA; ABÍLIO, 2005; RODRIGUES et al., 2012). De acordo com Hassler (2006, p. 87), o estudo da percepção propicia meios para avaliar as relações entre os indivíduos e a natureza que os cerca, relações estas que abrangem sentimentos e ideias em relação ao espaço vivido. Essas informações, quando direcionadas a um enfoque ambiental, podem contribuir para o diálogo entre as comunidades e os gestores de áreas protegidas (REMPEL et al., 2008; VODOUHÊ et al., 2010; SANTOS; MELO, 2016).

Sob esta perspectiva, a presente pesquisa foi conduzida junto à comunidade do entorno do Jardim Botânico do Recife (JBR), com o objetivo de

revista brasileira educação ambiental 
descrever e analisar as percepções dos mesmos sobre o JBR e o local onde vivem. Neste sentido, assumiu-se a hipótese de que os atributos de proteção e contemplação da natureza se destacam na percepção sobre o JBR entre os moradores de seu entorno, em contraste com a percepção sobre o local onde vivem - nos quais não se destacam atributos protetivos e contemplativos. Espera-se que as informações geradas possam contribuir com as estratégias de gestão do JBR, por meio de ações de Educação Ambiental voltadas para comunidade vizinha.

\section{Material e Métodos}

\section{Área de Estudo}

A pesquisa foi realizada na região onde está inserido o Jardim Botânico do Recife (JBR), situado na parte sudoeste da cidade do Recife, estado de Pernambuco, nordeste do Brasil (Figura 1). O JBR possui uma área total de 11,23 hectares. Em conjunto com um grupo de Unidades de Conservação Municipais, popularmente conhecidas como "Matas do Curado", o JBR forma um importante "cinturão verde" a oeste da cidade do Recife. Grande parte da área do JBR é ocupada por um fragmento de Mata Atlântica, caracterizado como Floresta Ombrófila Densa (VELOSO et al., 1991).

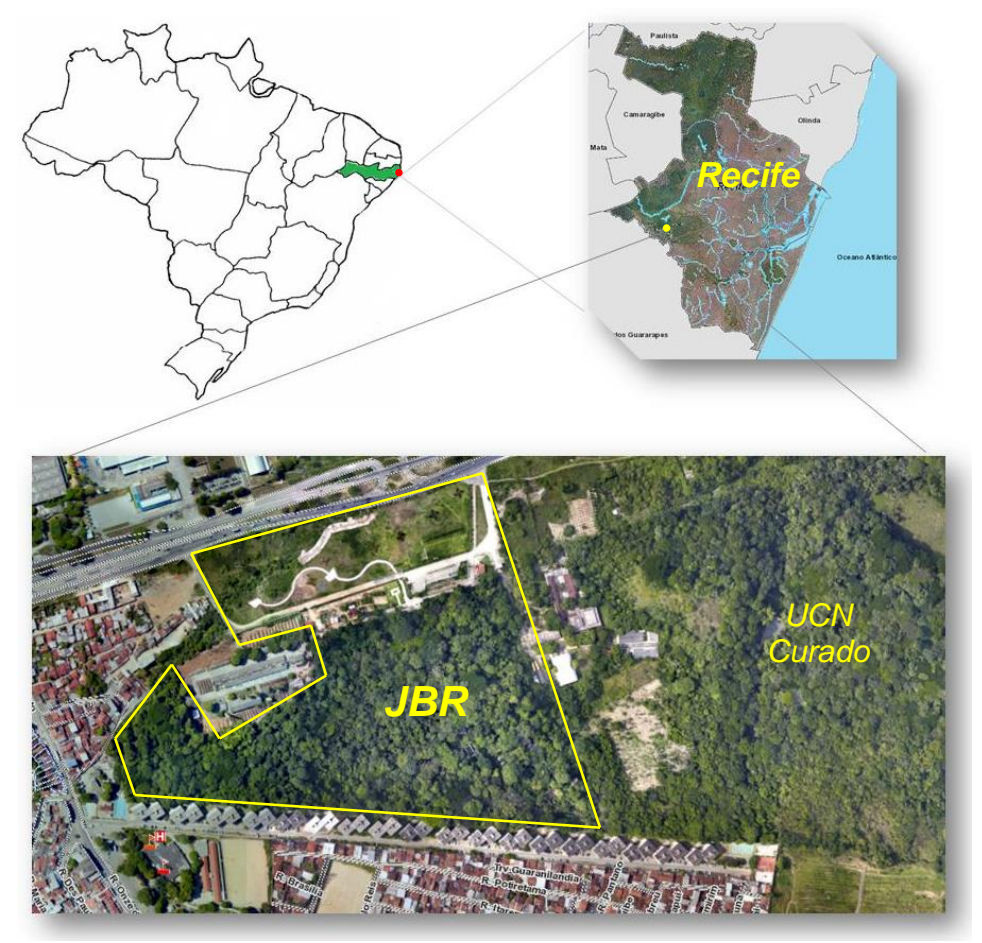

Figura 1: Localização do Jardim Botânico do Recife (JBR).

Fonte: autoria própria. 
A região do entorno é caracterizada por um nível de urbanização precário e predominância de comunidades de baixa renda - com exceção do conjunto residencial Jardim Botânico, cuja área faz divisa com o JBR, onde os moradores apresentam melhores condições socioeconômicas. Em virtude do histórico de pressões antrópicas ao ambiente, a instituição tem buscado alternativas para promover a integração dos moradores do entorno em ações e atividades educativas.

No JBR, são desenvolvidas diversas ações de Educação Ambiental junto ao público visitante, com ênfase na necessidade de conservação e preservação do meio ambiente. Entre os visitantes agendados, predominam alunos de escolas públicas, de diferentes faixas etárias, além de grupos diversos (visitantes não-agendados) vindos de diferentes partes do Recife e cidades vizinhas. Entre os principais atrativos, o JBR oferece a visitação aos jardins temáticos (ex. Plantas Medicinais, Palmeiras, Sensorial, Flores Tropicais, entre outros), coleções botânicas (cactos, bromélias e orquídeas), viveiro florestal, trilhas monitoradas no fragmento de Mata Atlântica, exposições de vídeos e palestras no Núcleo de Educação Ambiental (NEA). Aproximadamente 8.100 pessoas vistam o JBR todos os meses, conforme os dados da administração no balanço anual de 2014. Além das atividades de visitação e Educação Ambiental, também são desenvolvidas atividades de pesquisa, programas de conservação e reflorestamentos, entre outras ações.

\section{Coleta e análise dos dados}

A coleta dos dados foi realizada por meio da aplicação de questionários entre moradores do entorno do Jardim Botânico do Recife (JBR). Com o intuito de apreender os diferentes perfis socioeconômicos existentes na região, foram selecionados três locais para aplicação de questionários: 1) Conjunto Residencial Jardim Botânico; 2) Creche municipal do Centro Social Bidu Krause; e, 3) Escola Estadual Álvaro Negro Monte. Inicialmente, foram aplicados alguns questionários pilotos junto a uma pequena amostra de respondentes em cada local, de modo a avaliar a compreensão dos mesmos em relação às questões elaboradas. Com base nos primeiros resultados, os questionários foram ajustados em um formato definitivo, contendo questões fechadas, que buscaram definir o perfil socioeconômico, as experiências e percepções dos moradores relacionadas ao JBR e ao local onde vivem.

Os respondentes foram selecionados por conveniência, numa amostragem do tipo não-probabilistica (ALBUQUERQUE et al., 2010). Buscouse oportunizar a participação do maior número possível de informantes.

Os questionários foram entregues diretamente aos respondentes ou enviados indiretamente, em envelopes deixados nas caixas de correios do condomínio, na administração da creche (para que os pais ou responsáveis pudessem responder) e diretoria da escola. No envelope, além do questionário, continham as explicações sobre o propósito da pesquisa e as orientações básicas para o preenchimento e devolução do mesmo. Ressalta-se que a

revista brasileira educação ambiental 
participação foi voluntária e condicionada ao consentimento livre e esclarecido do uso das informações, declarada por meio da assinatura do participante. Ao final, foram obtidos 98 questionários.

Os dados foram analisados por meio de estatística descritiva, com o cálculo de médias e frequências. Foram elaborados gráficos com o uso do software Sigmaplot (Systat Software, Inc), versão 12.

As inferências sobre a percepção dos respondentes foram realizadas tendo como base as respostas predominantes para questões que buscaram investigar as associações relativas ao "JBR" e o "lugar onde vivem". Para isso, partiu-se da compreensão de que as respostas associativas correspondem a uma medida da percepção da realidade e dos estereótipos afetivos e emocionais, estando ligadas ao preconceito racionalizado, justificado ou criado pelos respondentes, conforme definido na abordagem da análise de conteúdo preconizada por Bardin (1997).

\section{Resultados e Discussão}

O perfil socioeconômico dos respondentes revelou que $65 \%$ pertenciam ao gênero feminino, apresentando média de idade de 30 anos (Figura 2, A), sendo a maioria natural do estado de Pernambuco $(76 \%, n=74)$, mais precisamente da cidade do Recife $(84 \%, n=62)$ (Figura 2, B). Quanto ao estado civil, $64 \%$ dos respondentes eram solteiros (Figura 2, C). Em relação ao nível de escolaridade, verificou-se que $40 \%(n=32)$ eram estudantes (Figura 2, F) e que $43 \%(n=42)$ não concluíram ou estavam cursando o ensino médio (Figura 2, D). Quanto à renda familiar (Figura 2, E), a maioria dos respondentes $53 \%(n=51)$ optou por não disponibilizar essa informação, contudo $30 \%$ ( $n=$ 29) dos $47 \%(n=46)$ que disponibilizaram, asseguraram possuir renda de até um salário mínimo. 

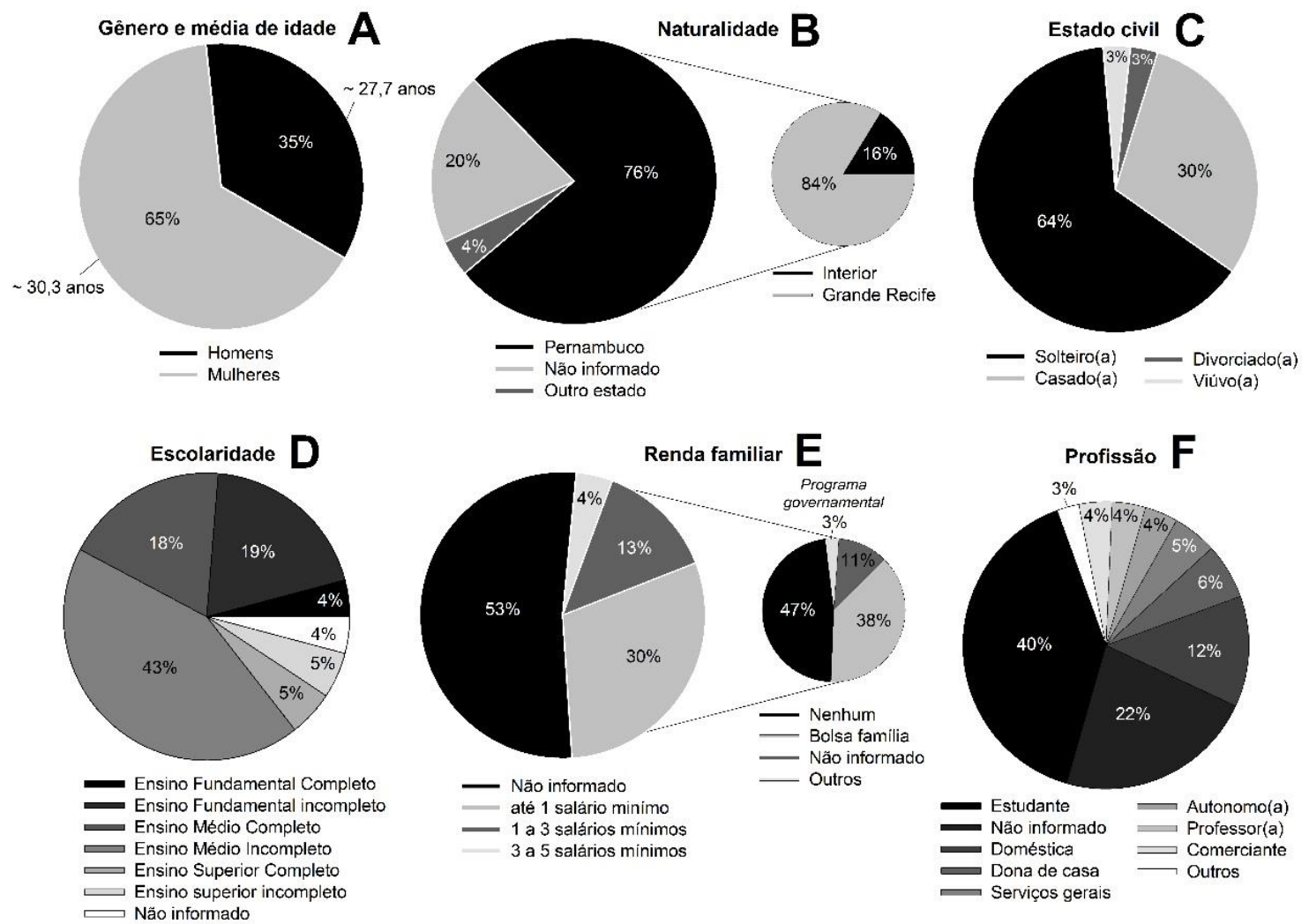

Figura 2: Perfil socioeconômico dos respondentes, moradores do entorno do Jardim Botânico do Recife (JBR). Em A, Gênero e média de idade do(a) entrevistado(a); B, Naturalidade; C,

Estado civil; D, Escolaridade; E, Renda familiar e F, Profissão. Fonte: autoria própria.

Quanto ao tempo de moradia, verificou-se que a maior parte dos respondentes $(57 \% ; n=54)$ reside no entorno do Jardim Botânico do Recife (JBR) a mais de 10 anos (Figura 3). Ressalta-se que esse tempo de moradia possivelmente contribuiu para construção de suas memórias e experiências relacionadas ao JBR e ao local onde vivem.

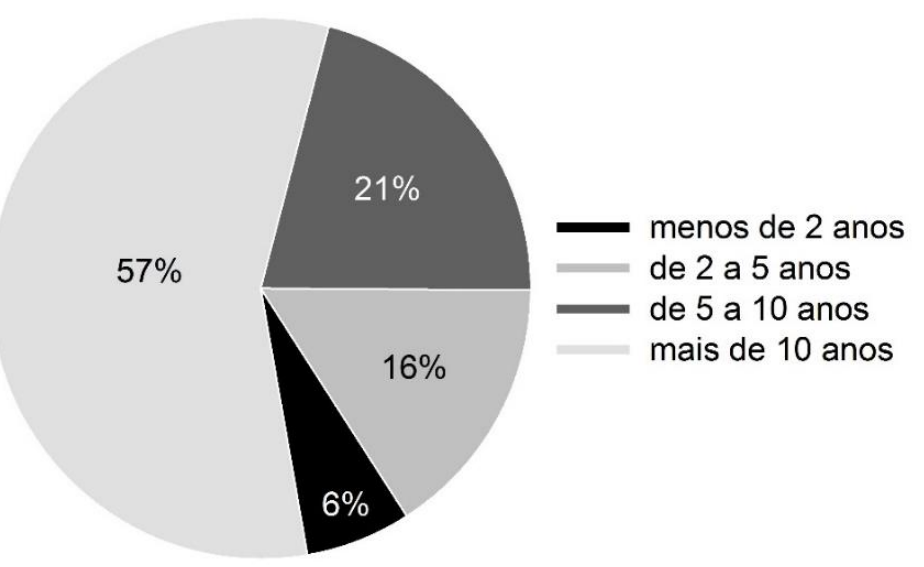

Figura 3: Distribuição dos respondentes quanto ao tempo de moradia no entorno do Jardim Botânico do Recife. Fonte: autoria própria.

Revbea, São Paulo, V. 11, № 4: 306-317, 2016.

revista brasileira

educação ambiental 
Quando estimulados a definir o local onde vivem, os respondentes destacaram atributos positivos, tais como: "calmo" $(17,1 \%$; $n=14)$, "agradável" $(15,85 \% ; n=13)$ e seguro $(13,41 \% ; n=11)$. Contraditoriamente, para essa mesma questão, obteve-se uma elevada frequência de respostas que definiram o local como "inseguro" $(17,1 \%$; $n=14)$ (Figura 4, A). Tal contradição nessas respostas pode ser um reflexo das diferentes formas de ocupação do território, onde uma parte dos respondentes reside em um condomínio fechado e com sistema particular de segurança, enquanto a outra parte não. Nota-se, entretanto, que o tema "segurança pública" assumiu relevante importância na relação dos informantes com o local onde vivem.

Para a questão "o que mais Ihe agrada no local onde vive?", destacaram-se: "Coleta de lixo" $(17,34 \%$; $n=17)$, "abastecimento de água" $(15,31 \% ; n=15)$, "sistema de transporte" $(14,29 \% ; n=14)$ e "ser um lugar calmo" $(12,24 \% ; n=12)$ (Figura 4, B). Outra evidência da importância que o tema "segurança pública" apresentou para os respondentes emergiu com as respostas para a questão "o que mais Ihe desagrada no local onde vive?". Neste quesito, predominaram associações com item "segurança" $(28,26 \%$; $\mathrm{n}=26)$, seguido de "sistema de saúde" $(20,65 \%$; n=19) e "coleta de lixo" $(10,87 \% ; n=10)$ (Figura 4, C).

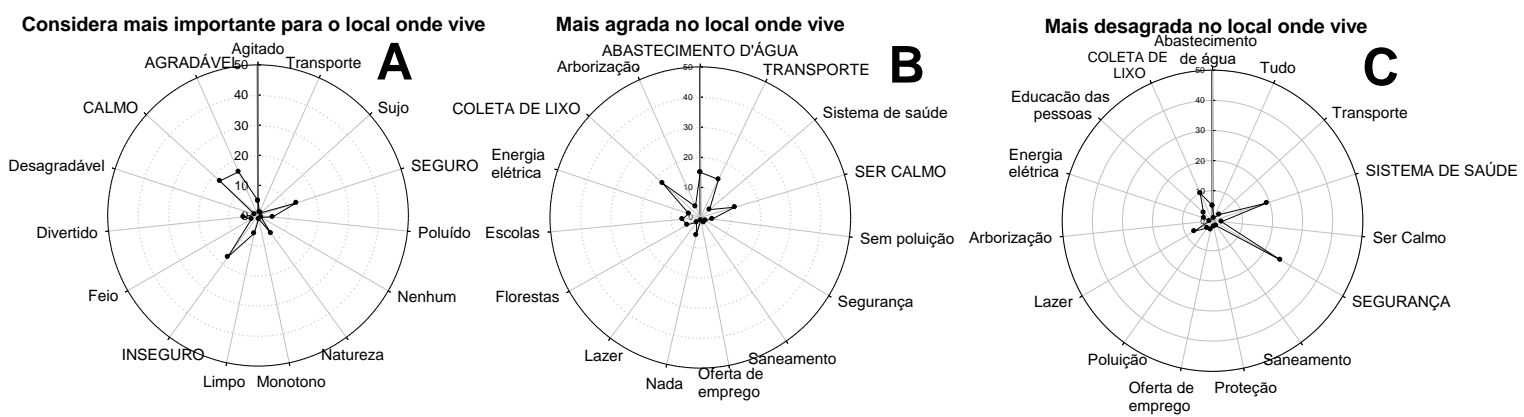

Figura 4: Distribuição das respostas relacionadas às percepções dos participantes sobre o local onde vivem. Fonte: autoria própria.

Quanto às experiências relacionadas ao Jardim Botânico do Recife (JBR), verificou-se que $51 \%(n=50)$ dos respondentes já haviam visitado a instituição, dentre os quais $32 \%(n=31)$ realizaram mais de três visitas. Aproximadamente $44 \%(n=43)$ das visitas haviam sido realizadas a mais de um ano, porém grande parte pretendia realizar visitas futuras $(90 \% ; n=88)$.

Conforme apresentado na Figura 5, a palavra "natureza" foi escolhida por $27,55 \%(n=27)$ dos respondentes para definir o JBR. Na percepção de $78,65 \%(n=70)$ a instituição pode ser comparada a uma "reserva florestal", e serve para "proteger a floresta, os animais e a natureza" $(55,55 \% ; n=45)$. Embora $38,46 \%(n=35)$ tenham no "lazer e diversão em contato com a natureza" o que mais Ihes agrada no JBR, $51,57 \%(n=49)$ consideraram que a instituição representa, para o local onde vivem, uma "oportunidade de aprender mais sobre plantas e meio ambiente". Ressalta que, $87,75 \% \quad(n=86)$ dos Revbea, São Paulo, V. 11, № 4: 306-317, 2016. 
respondentes afirmaram que, se convidados, participariam de atividades promovidas pelo JBR para os seus vizinhos.

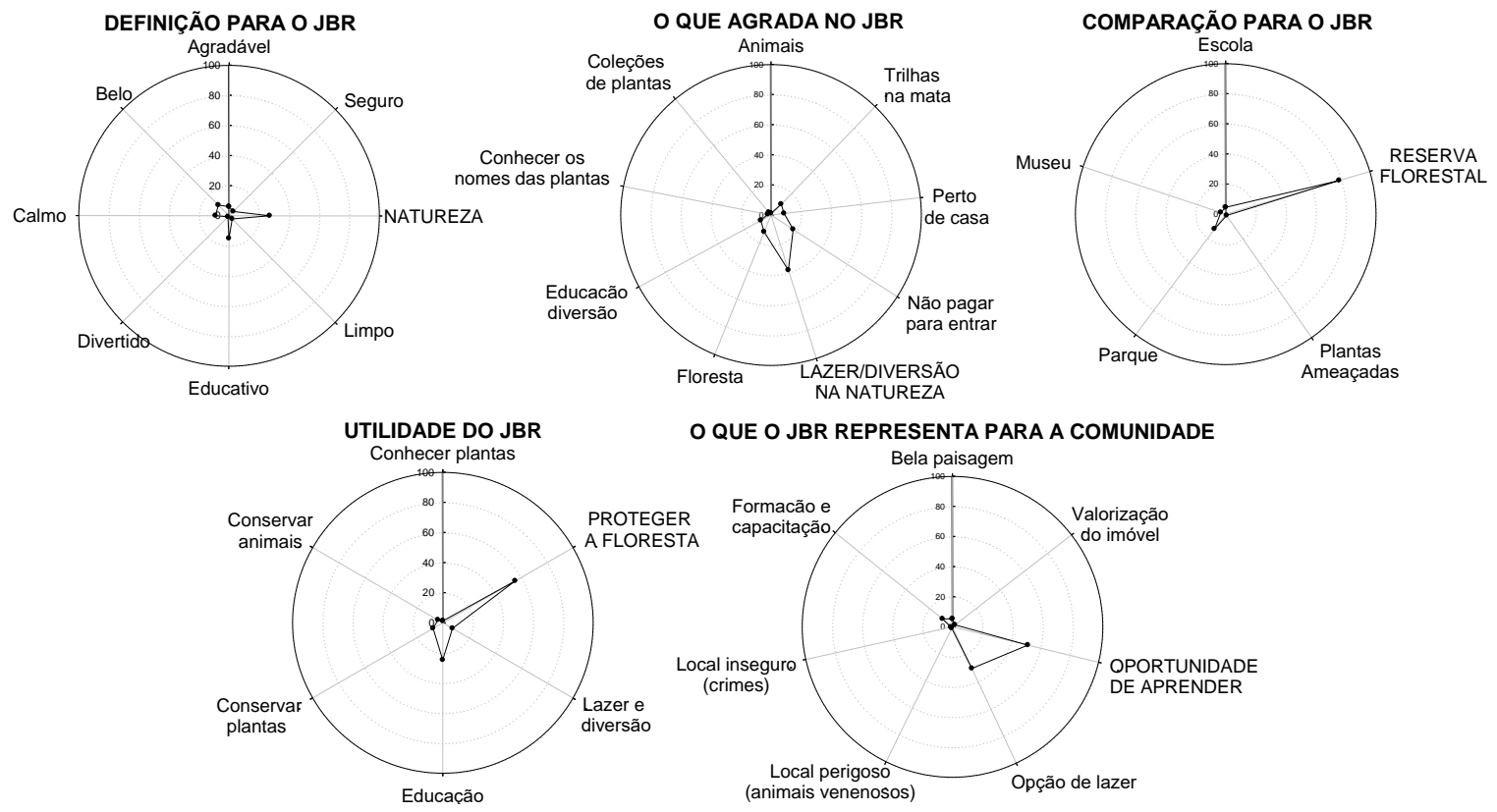

Figura 5: Distribuição das respostas relacionadas às percepções dos participantes sobre o Jardim Botânico do Recife (JBR). Fonte: autoria própria.

O predomínio de respostas que compararam o JBR a uma reserva florestal, com uma suposta utilidade protetiva, bem como o reconhecimento da sua importância para o aprendizado e o lazer em contato com a natureza, corrobora a hipótese do presente estudo - de que os atributos de proteção e contemplação da natureza se destacariam na percepção dos respondentes sobre o Jardim Botânico do Recife. Além de demonstrarem uma relação positiva dos respondentes com o JBR, esses resultados revelaram a importância do fragmento de Mata Atlântica inserido na instituição, que representou um elemento central na percepção dos respondentes.

Neste sentido, Chen et al. (2009, p. 584) destacam a importância das reservas florestais como estratégia de conservação in situ nos jardins botânicos tropicais. Segundo esses autores essas áreas permitem a promoção de iniciativas como a reintrodução de espécies nativas importantes ou valiosas, apresentando consideravel eficiência na missão de preservar a biodiversidade tropical por meio do manejo de ecossistemas locais. Conforme verificado no presente estudo, o elemento florestal assume uma posição de destaque nas representações e experiências dos moradores do entorno sobre o JBR, sendo um dos atrativos mais procurados pelos visitantes, para realização de trilhas 
monitoradas e caminhadas ecológicas. Além disso, diversas ações de manejo da biodiversidade são desenvolvidas nesse remanescente florestal.

Cabe ressaltar, adicionalmente, que o modelo de conservação in situ, verificado em muitos jardins botânicos tropicais (CHEN et al., 2009), geralmente parte de uma concepção de que os atributos naturais da área devem ser protegidos para que possam ser contemplados pelos visitantes. Salienta-se que, em contextos de proteção restritiva, as comunidades vizinhas podem desenvolver uma percepção negativa em relação às áreas protegidas, criando conflitos com os gestores (LIU et al., 2010). Diante de tais experiências, muitos estudos consideram que as populações do entorno de áreas protegidas precisam de atenção especial, e que sua exclusão das estratégias de conservação podem dificultar a efetivação das medidas legais (DIEGUES, 2008). Não obstante, no presente estudo, os moradores do entorno do JBR vêm na área uma oportunidade de lazer e aprendizado em contato com a natureza e não manifestaram opiniões negativas sobre a instituição, apesar de reconhecerem o carater restritivo do modelo de conservação do JBR.

Diante disso, pode-se considerar que o fato do JBR estar inserido em um ambiente urbano - em uma cidade que apresenta uma carência de áreas verdes qualificadas para visitação - exerce forte influência sobre a percepção dos respondentes. Segundo Agbenyega et al. (2009, p. 557), em ambientes urbanos a proteção de áreas verdes assume um papel importante para a população residente, sendo muito apreciada por proporcionar uma opção de lazer. Conforme verificado na percepção dos informantes sobre o local onde vivem, a região do estudo está inserida em um meio com problemas de segurança e serviços públicos precários. Tais representações revelaram parte das tensões sociais que se fazem presentes no cotidiano dos moradores do entorno do JBR. Neste contexto, o JBR assume um aparente status de refúgio natural que proporciona lazer e diversão em contato com a natureza.

\section{Conclusão}

A visão integrada das percepções e experiências dos respondentes demonstrou que predominam concepções positivas em relação ao JBR. Todavia, também foram reveladas concepções negativas em relação ao local onde vivem, ligadas principalmente à falta de segurança e serviços públicos precários.

O elemento florestal se destacou na percepção dos participantes em relação ao JBR. Neste sentido, o serviço de conservação in situ promovido pela instituição, que mantém um remanescente de mata atlântica no seu interior, aparentemente exerce forte influência sobre a forma como os moradores do entorno percebem o JBR. A elevada frequência de respostas que se referem ao JBR como uma instituição encarregada de "proteger a floresta, os animais e a natureza", bem como para realização de atividade de "lazer e diversão em contato com a natureza", confirmam a hipótese do presente estudo. 
Conclui-se que a conservação da floresta deve ser usada como tema central nas ações de Educação Ambiental e estratégias de sensibilização da comunidade do entorno. Pode-se ressaltar, nestas ações, a importância do serviço prestado pelas florestas e pelo JBR na conservação da biodiversidade e na melhoria da qualidade de vida da população em um meio urbano, bem como o papel das comunidades vizinhas como parceiras para o êxito dessas ações e qualificação contínua dessas áreas.

\section{Agradecimentos}

Os autores agradecem ao Jardim Botânico do Recife (JBR) e à Fundação de Amparo à Ciência e Tecnologia do Estado de Pernambuco (FACEPE) pelo apoio estrutural e financeiro no desenvolvimento desta pesquisa, bem como aos moradores do entorno participantes da pesquisa, pela cooperação no fornecimento dos dados.

\section{Referências}

AGBENYEGA, O.; BURGESS, P. J.; COOK, M.; MORRIS, J. Application of an ecosystem function framework to perceptions of community woodlands. Land use policy. 26: 551-557, agosto/2009.

ALBUQUERQUE, U.P.; LUCENA, R.F.P.; NETO, E.M.F.L. Seleção dos participantes da pesquisa. In: ALBUQUERQUE, U.P.; LUCENA, R.F.P.; CUNHA, L.V.F.C. (ed) Métodos e técnicas na pesquisa etnobotânica. Recife, NUPEEA, 2010.

BARDIN, L. Análise de conteúdo. Lisboa, Persona. 1977.

BEDIAGA, B. Conciliar o útil ao agradável e fazer ciência: Jardim Botânico do Rio de Janeiro - 1808 a 1860. História, Ciências, Saúde - Manguinhos. Rio de Janeiro, 14 (4): 1131-1157, dezembro/2007.

CERATI, T.M.; LAZARINI, R.A.M. A pesquisa-ação em Educação Ambiental: uma experiência no entorno de uma unidade de conservação urbana. Ciência \& Educação, São Paulo, 15 (2): 383-392, agosto/2009.

CHEN, J.; CANNON, C.H.; HU, H. Tropical botanical gardens: at the in situ ecosystem management frontier. Trends in Plant Science. Berkeley, CA, USA, 14 (11): 584 - 589, setembro/2009.

DIEGUES, A.C. 0 mito moderno da natureza intocada. 6 ed. São Paulo, Hucitec: NUPAUB-USP/CEC, 2008.

GUERRA, R.A.T; ABÍLIO, F.J.P. A percepção ambiental de professores de escolas públicas de ensino fundamental de Cabedelo, Paraíba. In: GUERRA, 
R.A.T; ABÍLIO, F.J.P. (Org). A Questão Ambiental no Ensino de Ciências: A formação continuada de professores de ensino fundamental. João Pessoa, UFPB/FUNAPE/LEAL, v. 1, p. 91-104, 2005.

HASSLER, M.L. A natureza na cidade: uma abordagem a partir da percepção da população acerca do Jardim Botânico de Curitiba (PR). Sociedade \& Natureza, Uberlândia, 18 (35): 79-96, dezembro/ 2006.

JACKSON, P.W.; KENNEDY, K. The Global Strategy for Plant Conservation: a challenge and opportunity for the international community. Trends in Plant Science. Berkeley, CA, USA,14 (11): setembro/2009.

LIU, J.; OUYANG, Z; MIAO, H. Environmental attitudes of stakeholders and their perceptions regarding protected area-community conflicts: a case study in China. Journal of Environmental Management, 91:2254-2262, julho/2010.

MARTINS, A.L.L. Lazer e área protegida: conflitos na busca de "emoções agradáveis". Ambiente \& Sociedade [online]. Campinas, 14 (2): 51-67. Dezembro/2011.

MEUNIER, I.M.J.; SILVA, H.C.G. Horto D'el Rey de Olinda, Pernambuco: história, estado atual e potencialidades da cobertura vegetal de uma área verde urbana (quase) esquecida. REVSBAU. Piracicaba, SP, 4(2): 62-81, maio/2009.

REMPEL, C.; MÜLLER, C.; CLEBSCH, C.; DALLAROSA, J; RODRIGUES, M. S; CORONAS, M.V.; RODRIGUES, G.G.; GUERRA, T.; HARTZ, S.M. Percepção Ambiental da Comunidade Escolar Municipal sobre a Floresta Nacional de Canela, RS. Revista Brasileira de Biociências. Porto Alegre, 6: 141-147, junho/2008.

RODRIGUES, J.; DUTRA, M.; ALBUQUERQUE, P.; DIAS, S.; ALMEIDA, A.V. Aspectos histórico-ecológicos do Horto d'El Rey de Olinda, Pernambuco. Mneme - Revista de Humanidades. Caicó, RN, 7.(19): 388-413, janeiro/2006.

RODRIGUES, M.L.; MALHEIROS, T.F.; FERNANDES, V.; DARÓS, T.D. A percepção ambiental como instrumento de apoio na gestão e na formulação de políticas públicas ambientais. Saúde Sociedade, São Paulo, 21(3): 96-110, 2012.

SAÍSSE, M.V.; RUEDA, M.M. Educação Ambiental em Jardins Botânicos. Um caso brasileiro. Ambientalmente sustentable, La Coruña, Espanha, 2 (6): 7 19, dezembro/2008.

SANTOS, R.D.; MELO, I.B.N. Percepção ambiental na gestão de resíduos sólidos: estudo de caso num clube de campo de uma cidade do estado de São Paulo. Revista Brasileira de Educação Ambiental, São Paulo, 11(1): 264283, 2016. 
VEIGA, R.F.A.; COSTA, A.A.; BENATTI-JÚNIOR, R.; MURATA, I.M.; PIRES, E.G.; ROMA, R.P.C.R. Os jardins botânicos brasileiros. O Agronômico, Campinas, 55(1): 56 - 60, 2003.

VELOSO, H. P.; RANGEL FILHO, A. L. R.; LIMA, J. C. A. Classificação da vegetação brasileira adaptada a um sistema universal. São Paulo, Fundação Instituto Brasileiro de Geografia e Estatística, 1991.

VIVACQUA, M; VIEIRA, P.F. Conflitos socioambientais em Unidades de Conservação. Política \& Sociedade. 7: 139 - 162, outubro/2005.

VODOUHÊ, F.G.; COULIBALY, O.; ADÉGBIDI, A; SINSIN, B. Community perception of biodiversity conservation within protected areas in Benin. Forest Policy and Economics, 12: 505-512, junho/2010.

WILLISON, J. Educação Ambiental em Jardins Botânicos: Diretrizes para Desenvolvimento de Estratégias Individuais. Rio de Janeiro: Rede Brasileira de Jardins Botânicos, 2003. Disponível em: http://www.agencia.cnptia.embrapa.br/recursos/EDUAMB JBIDQUbXHIMas.pdf. Acesso em 31.03.2016. 